Research Article

\title{
Isolation and Molecular Identification and Antimicrobial Susceptibility of Providencia spp. from Raw Cow's Milk in Baghdad, Iraq
}

\author{
Nagham Mohammed Ayyal Al-Gburi \\ Zoonotic Diseases Unite, College of Veterinary Medicine, Baghdad University, Baghdad, Iraq \\ Correspondence should be addressed to Nagham Mohammed Ayyal Al-Gburi; drvet2011@yahoo.com
}

Received 20 May 2020; Revised 24 September 2020; Accepted 28 October 2020; Published 19 November 2020

Academic Editor: Nora Mestorino

Copyright (c) 2020 Nagham Mohammed Ayyal Al-Gburi. This is an open access article distributed under the Creative Commons Attribution License, which permits unrestricted use, distribution, and reproduction in any medium, provided the original work is properly cited.

\begin{abstract}
A total of sixty raw milk samples were collected from (street vendors and shops) from Baghdad city, Iraq. The samples were inoculated into peptone water and, then, subcultured onto MacConkey agar and Blood agar. Identification of isolates was confirmed by microscopic examination, cultural characteristic, biochemical tests, Vitek (VITEK ${ }^{\circledR} 2$ system), and Biolog GN substrate reactions followed by $16 \mathrm{~S}$ rRNA and specific genes sequencing. Of 60 raw cow's milk samples, Providencia spp. were identified only in 4 samples (6.67\%) and P. rettgeri was the most common, 2/4 (50\%), followed by P. stuartii and P. vermicola, $1 / 4$ (25\%). Antimicrobial susceptibility tests were conducted against ten antibiotics by the disc diffusion method. All Providencia isolates showed multidrug resistance (MDR), and the absolute resistant was 100\% to tetracycline, erythromycin, and doxycycline and 50\% against ampicillin $\backslash$ sulbactam and amoxicillin/clavulanic acid. They were highly susceptible (100\%) to trimethoprim, imipenem, and chloramphenicol. These findings indicate that milk might be contaminated with Providencia spp. leading to transmission to humans causing poisoning, diarrhea, and other infections. This is the first study of isolated Providencia spp. from raw cow's milk.
\end{abstract}

\section{Introduction}

Before 2005, the genus Providencia was including six species; after that, a new species was identified to become nine species which are $P$. alcalifaciens, $P$. rustigianii, $P$. stuartii, $P$. rettgeri, $P$. friedericiana, $P$. heimbachae, $P$. vermicola, P. sneebia, and P. thailandensis [1-3]. The Providencia spp. are urease-producing Gram-negative, belonging to the family Enterobacteriaceae. Although these species are present as normal flora in the human intestinal tract, they are opportunistic pathogens, especially in immunocompromised people causing traveler's diarrhea, gastroenteritis and infection of the urinary tract and endocardium, sepsis in neonatal, and ocular inflammations [4-9]. Animals such as cattle, sheep, insects, worms, cats, birds, dogs, guinea pigs, and reptiles are reservoirs to Providencia spp., as well as this bacterium present in environment such as water (river, cows, and waste) [10-14]. These may explain the isolation of them from different food and food products [9, 15-17].

The laboratory identification of Providencia spp. is depending on culturing and biochemical characteristics. Providencia spp. grow in enteric agars such as MacConkey, Salmonella-Shigella (SS), Eosin Methylene Blue (EMB), and Hektoen Enteric (HE), and selective agars are Simmons Citrate, Tergitol, and HardyCHROM ${ }^{\mathrm{TM}}$ UTI $[18,19]$. The commercial identification kits currently available include the Analytical Profile Index (API20) Esystem, Vitek GNI and GNI1 cards, and Microscan Rapid Neg ID3panel [20-23] in addition to the molecular identification using $16 \mathrm{~S}$ rRNA and specific species genes [10, 24, 25].

Providencia spp. reported resistant to antimicrobials and multidrug resistance (MDR), and both $P$. stuartii and $P$. rettgeri reported resistant against many antimicrobial drugs. Providencia isolates were investigated to be MDR 
(75\%) $[26,27]$. P. rettgeri isolates are found highly resistant against several antimicrobials such as gentamicin, imipenem, polymyxin, tetracycline, nitrofurantoin vancomycin, bacitracin, erythromycin, novobiocin, rifampin, and colistin $[28,29]$. P. vermicola has reported $100 \%$ resistance to ampicillin, kanamycin, nalidixic acid, and neomycin [25]. Carbapenem-resistant $P$. stuartii and $P$. rettgeri were reported; therefore, the treatment has been a problem because MDR is a significant public health challenge [30-32]. Milk has been considered the most nutritious and balanced food being rich in essentials that are important for humans [33].

Milk is considered as a perfect environment for the growth and survival of many microorganisms that are a threat to the public health [34-36]. Contamination of milk with microorganisms occurs via a variety of environmental sources, including soils, water, moisture content, milking apparatus, and surrounding air condition [33, 37, 38]. There are rare investigations of Providencia spp. in raw cow's milk, especially in Iraq. It has been found that Providencia spp. is one of the bacteria that were isolated from subclinical mastitis [39, 40]. This study was conducted to detect the presence of Providencia spp. in raw cow's milk and determine the antimicrobial susceptibility to antibiotics.

\section{Materials and Methods}

2.1. Isolation and Morphological Identification. Sixty raw milk samples were collected from vendors and shops in Baghdad city from March to June 2019. Ten ml of milk samples was taken and inoculated into peptone water, incubated at $37^{\circ} \mathrm{C}$ for $24 \mathrm{hrs}$, then subcultured on MacConkey agar and Blood agar (HiMedia, India), and incubated at $37^{\circ} \mathrm{C}$ for $24 \mathrm{hrs}$. The suspected Providencia spp. colonies which appear as pale colonies, lactose nonfermenter on MacConkey agar were picked, and conventional biochemical tests were applied including urease, phenylalanine, and triple sugar iron (TSI). They were further identified using the VITEK ${ }^{\circledR} 2$ system and Biolog GN substrate (Biomerieux, France) reactions for more differentiation according to $[1,41]$.

2.2. Molecular Identification. Molecular identification was applied on three isolates to confirm and differentiate between them. DNA was extracted from isolates growth using the Wizard Genomic DNA Purification Kit protocol (Promega, USA). PCR amplification of bacterial 16S rRNA was applied with 27 forward primer AGAGTTTGATCCTGGCTCAG and 1492 reverse primer TACGGTTACCTTGTTACGACTT 1, $300 \mathrm{bp}$. The PCR reaction mixture final volume of $25 \mu \mathrm{l}$ contains PCRpremix $12.5 \mu \mathrm{l}$, forward primer $1 \mu \mathrm{l}$, reverse primer $1 \mu \mathrm{l}$, nuclease free water $8.5 \mu \mathrm{l}$, and DNA $2 \mu \mathrm{l}$. The PCR scheme performed was as follows: $95^{\circ} \mathrm{C}$ for $5 \mathrm{~min} / 1$ cycle; $95^{\circ} \mathrm{C}$ for $30 \mathrm{sec} / 30$ cycles; and $60^{\circ} \mathrm{C}$ for $45 \mathrm{sec} / 30$ cycles and extension at $72^{\circ} \mathrm{C}$ for $1 \mathrm{~min} / 30$ cycles and final extension $72^{\circ} \mathrm{C}$ for $7 \mathrm{~min} / 1$ cycle [42]. After amplification, 1\% agarose gel electrophoresis was applied to confirm the presence of amplification. Then, the PCR products were purified and sent to be sequenced.
Provi_forward primer CGCATAATCTCTTAGGAGCAAA and Provi_reverse primer ATGAATCACAAAGTGGTAAGCG (size 1306 bp) were used to detect both $P$. rettgeri/P. vermicola, Provi_foward primer and P_Vermi_reverse primer (AAGGAGR (A/G) TGATCCAGCCGCAG) (size 1366 bp) were used to detect if the isolates are $P$. vermicola or not. The PCR reaction mixture volume of $20 \mu \mathrm{l}$ included PCRpremix $10 \mu \mathrm{l}$, nuclease free water $6 \mu \mathrm{l}$, forward and reverse primer $1 \mu \mathrm{l}$ to each and DNA $2 \mu \mathrm{l}$. The PCR scheme performed was as follows: initial denaturation at $95^{\circ} \mathrm{C}$ for $5 \mathrm{~min}$, denaturation at $95^{\circ} \mathrm{C}$ for $30 \mathrm{sec}$, annealing at $62^{\circ} \mathrm{C}$ for $30 \mathrm{sec}\left(68^{\circ} \mathrm{C}\right.$ for $30 \mathrm{sec}$ for Provi_foward primer and P_Vermi_reverse primer), extension at $72^{\circ} \mathrm{C}$ for $1 \mathrm{~min}$, and final extension $72^{\circ} \mathrm{C}$ for $7 \mathrm{~min}[25]$.

After amplification, 1\% agarose gel electrophoresis was applied to confirm the presence of amplification, then PCR products were purified and sent to sequenced, and the results were analyzed using genius software and compared to known sequences in the GenBank and Sepsitest BLAST databases.

2.3. Detected Antimicrobial Susceptibility. Susceptibility against antimicrobial drugs was determined by disk diffusion protocol using Mueller-Hinton $(\mathrm{MH})$ agar (Oxoid, UK). The inhibitory zones around these antimicrobial discs were measured using a millimeter $(\mathrm{mm})$ unit utilizing a metric ruler, and the results were read $[43,44]$. Ten antibiotic disks (Merseyside, U.K.) used included amoxicillin $20 \mu \mathrm{g}$, clavulanic acid $10 \mu \mathrm{g}$ (AUG 30C), trimethoprim (TM, $15 \mu \mathrm{g}$ ), ampicillin $10 \mu \mathrm{g} \backslash$ sulbactam $10 \mu \mathrm{g}$ (SAM, 20 C), tetracycline $(T, 30 \mu \mathrm{g})$, erythromycin $(E, 10 \mu \mathrm{g})$, cefixime (CFM $5 \mu \mathrm{g})$, doxycycline (DXT, $30 \mu \mathrm{g})$, imipenem (IPM, $10 \mu \mathrm{g})$, chloramphenicol (C $30 \mu \mathrm{g}$ ), and streptomycin (S $25 \mu \mathrm{g}$ ). Multidrug resistance (MDR) was detected according to the work of Magiorakos et al. [45]. The isolates resistant against three or more separate antimicrobial classes are considered as MDR. The multiple antibiotics resistance (MAR) index was calculated by dividing (a): the number of antimicrobial drugs resistant of isolate by (b): the total number of antimicrobial drugs, where the same isolate which exposed the results more than 0.2 was considered high risk [46].

\section{Results}

3.1. Characterization and Molecular Identification of Providencia Species. Providencia species were identified in 4 $(6.67 \%)$, P. rettgeri were the most dominant species, $2 / 4$ (50\%), and $P$. stuartii and $P$. vermicola were $1 / 4$ (25\%). The isolates were Gram-negative coccobacilli. On MacConkey agar, lactose nonferment colonies are circular with entire edges, shining, smooth, slim, and convex, $P$. vermicola showed a dense brownish center and hyaline periphery colonies, and the isolate on blood agar are nonheamolysis. Biochemically, it is motile, negative reactions for oxidase, positive for catalase and tryptophan deaminase, on TSI, gives alkaline/acid (pink/yellow) reaction without $\mathrm{H}_{2} \mathrm{~S}$ and gases production, the isolates were suspected of Providencia spp., 
and by using the VITEK ${ }^{\circledR} 2$ system, reactions give the positive for three isolates of $P$. rettgeri and one isolate was $P$. stuartii.

$P$. rettgeri isolates (unfortunately, $P$. stuartii isolate died before completing molecular identification) were sent to be sequenced and analyzed for similarity using a database at the NCBI. The partial gene sequence of 16S rRNA established that these isolates had high similarity between $P$. rettgeri/P. vermicola in both databases, when using Provi_foward and Provi_reverse (detected both $P$. rettgeri and $P$. vermicola), and a band of approximately $1306 \mathrm{bp}$ was observed on the agarose gel (Figure 1). The results of the sequence were as follows: $1^{\text {st }}$ isolate was $99.91 \%$ similar with $P$. rettgeri, the $2^{\text {nd }}$ gave $100 \%$ similarity to $P$. rettgeri/P. vermicola, while the $3^{\text {rd }}$ isolate was $99.81 \%$ similar to $P$. vermicola/P. rettgeri in the Gen bank database and in the Sepsi test BLAST database; similarity were as follows: the $1^{\text {st }}$ was $P$. vermicola/P. rettgeri, $99.5 \%$; the $2^{\text {nd }}$ was $P$. vermicola/P. rettgeri, $99.9 \%$, while the $3^{\text {rd }}$ was P. vermicola, $99.8 \%$, and when using Provi_forward and P_Vermi_reverse primer (detected only P. vermicola), the $1^{\text {st }}$ and $2^{\text {nd }}$ isolates give no bands, that is, these two isolates were $P$. rettgeri, while the $3^{\text {rd }}$ one gives two bands, which were not of the same expected size of $1366 \mathrm{bp}$; therefore, this isolate was more differentiated from $P$. rettgeri based on Biolog GN substrate reactions for more biochemical tests, and the sequencing result gives that the $3^{\text {rd }}$ isolate was $P$. vermicola, $99.8 \%$; thus, the three isolates were deposited in GenBank with accession nos:MT032351.1, MT032352.1, and MT032359.

3.2. Antimicrobial Susceptibility. As total, all Providencia isolates showed absolute resistance (100\%) against tetracycline, erythromycin, and doxycycline, 50\% to Amoxicillin \clavulanic acid and ampicillin \sulbactam, and $25 \%$ to cefixime. $P$. vermicola was resistant $100 \%$ to amoxicillin $20 \mu \mathrm{g} \backslash$ clavulanic acid and ampicillin $\backslash$ sulbactam compared with $P$. rettgeri which was $50 \%$ and $P$. stuartii was $0 \%$. The resistance against streptomycin reported $50 \%$ in $P$. rettgeri. Also, resistance to cefixime was $100 \%$ against $P$. vermicola, while $0 \%$ (sensitive) in both $P$. rettgeri and $P$. stuartii. All isolates were $0 \%$ resistant $(100 \%$ sensitivity) to trimethoprem, imipenem, and chloramphenicol. The results also revealed that these isolates were MDR. MAR index values were 0.6 in $P$. rettgeri and $P$. vermicola and 0.3 in $P$. stuartii that reveals all isolates were high risk (Table 1 ).

\section{Discussion}

Infections with Providencia spp. including $P$. rettgeri and $P$. stuartii which cause food poisoning, diarrhea, and UTI have been increased in the world, especially in developed and developing countries [9, 32, 47-51]. P. vermicola was investigated for the first time in infective nematodes, later from a diseased fresh water fish and from an acute watery diarrhea patient $[1,25,52]$. Therefore, in the present study, we investigate for Providencia spp. in raw milk collected from shops and vendors in Baghdad city. Our results indicate that raw milk is contaminated with $P$. rettgeri,

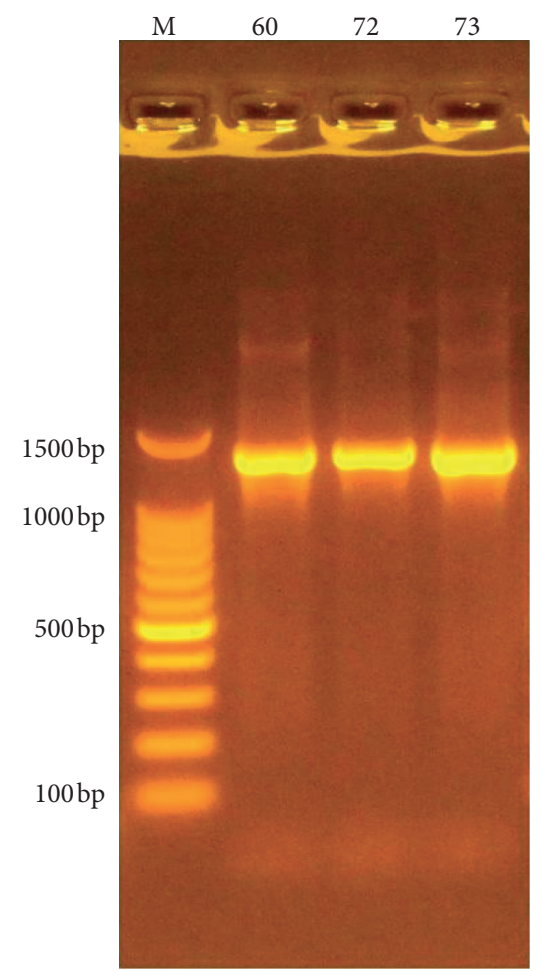

Figure 1: The amplification of species-specific primer1306 bp for $P$. rettgeri/P. vermicola genes of isolates, fractionated on agarose gel electrophoresis $1 \%$ stained with Eth. Br, M 100 bp DNA marker (60, 72, and 73 refer to the no. of Providencia species isolates).

P. stuartii, and P. vermicola. Providencia spp. including $P$. rettgeri and $P$. stuartii were isolated from food $[9,15-17,53,54]$. In Iraq, out of bacterial content of fish gut, $P$. rettgeri reported $1 / 50$ [55]. This is the first report of isolated Providencia from raw milk in Iraq; there is a study in Kenya, where $0.6 \%$ Providencia spp. was isolated from the milk of goats with subclinical mastitis, and $2 \%$ P. stuartii and $P$. alcalifacians were isolated from clinical healthy cows (subclinical mastitis) in Algeria [39, 40]. This study is also the first isolating $P$. vermicola from a food source such as milk. Milk may be contaminated by the environment such as soil, water, feces of the carrier or infected cattle, unhygienic conditions during milking, or used contaminated containers.

Phylogenetically, the family of Enterobacteriaceae has a highest similarity (16S rRNA gene sequence similarity), particularly with the members of genus Providencia (>98.1\%), and a higher similarity $99.5 \%$ was found between $P$. rettgeri and $P$. vermicola [1]. In agreement with that found in the present study, the similarity was ranging from 99.81 to 99.9\% even in used species-specific gene. In contrast, the primer Provi_foward and P_Vermi_revers primers confirmed that the two isolates were $P$. rettgeri (no bands), but the $3^{\text {rd }}$ one gives more one band in suspected $P$. vermicola. For this reason and because of the fact that the VITEK ${ }^{\circledR 2}$ system does not contain automated identification of $P$. vermicola in the list of card Gram negative, we used Biolog GN substrate reactions for more biochemical tests to differentiate $P$. vermicola from $P$. rettgeri such as urease, 
Table 1: Antimicrobial susceptibility results of Providencia spp. isolated from milk.

\begin{tabular}{|c|c|c|c|c|}
\hline \multirow{2}{*}{ Antibiotic } & \multicolumn{4}{|c|}{ Resistance (\%) } \\
\hline & P. rettgeri $[2]$ & P. vermicola [1] & P. stuartii [1] & Total \\
\hline Amoxicillin/clavulanic acid & 50 & 100 & 0 & 50 \\
\hline Streptomycin & 50 & 0 & 0 & 0 \\
\hline Trimethoprim & 0 & 0 & 0 & 0 \\
\hline Ampicillin $\backslash$ sulbactam & 50 & 100 & 0 & 50 \\
\hline Tetracycline & 100 & 100 & 100 & 100 \\
\hline Erythromycin & 100 & 100 & 100 & 100 \\
\hline Cefixime & 0 & 100 & 0 & 25 \\
\hline Doxycycline & 100 & 100 & 100 & 100 \\
\hline Imipenem & 0 & 0 & 0 & 0 \\
\hline Chloramphenicol & 0 & 0 & 0 & 0 \\
\hline MAR index & 0.6 & 0.6 & 0.3 & \\
\hline
\end{tabular}

erythritol and 2-ketogluconate, L-arabinose, D-glucosaminic acid, and D-glucuronic acid reactions and depending on the cultural characterization according to [1, 41]. In addition to the sequence, results confirmed that this isolate was $P$. vermicola.

In the current study, the results showed multiple resistance to antibiotics with high risk, these results were similar to other research studies, and resistance against multiple antimicrobials including tetracycline, ampicillin, and streptomycin were recorded in Providencia isolates in farm animals [56]. On the other hand, MDR $P$. rettgeri from UTI patients recorded high resistance to amikacin, aztreonam, cephalosporins, ciprofloxacin, ertapenem, and meropenem [41]. MDR (43\%) showed in Providencia spp. including $P$. stuartii and $P$. rettgeri isolated from retail meats, and most of the isolates were resistant (91\%) against tetracycline, ampicillin (69\%), and streptomycin (49\%) [54].

In addition, the results are similar with some differences in percentage of resistance to the study in Iraq; $P$. alcalifaciens and $P$. rettgeri isolated from clinical sputum and wastewater showed a high resistance against nitrofurantoin (100\%), ampicillin (94.4\%), amoxicillin/clavulanic acid $(72.2 \%)$, and ampicillin/sulbactam and tetracycline (38.8\% and $33.3 \%)$, respectively, while resistance to imipenem and cefotaxime were $5.6 \%$ each, and the most effective antibiotics were $100 \%$ resistant to norfloxacin, chloramphenicol, and cefixim and $88.9 \%$ resistant to trimethoprim recorded by the authors in [14] which are accordance with our results. High drug resistance against chloramphenicol, trimethoprim, and tetracycline and susceptibility to streptomycin of $P$. vermicola were recorded in diarrheal patients [25]. Despite MDR and the risk of the Providencia spp. isolates, all the isolates were susceptible to important antimicrobials which are used clinically such as imipenem, trimethoprim, and chloramphenicol in the present study.

\section{Conclusions}

Our results showed that raw milk is a potential source of Providencia spp. that may lead to infection in humans and risk to public health, especially the bacteria found as MDR. The present Providencia spp. in milk may be attributed to contamination after milking from the environment such as animal feces, or it is source from subclinical mastitis cow.

\section{Recommendations}

More studies should be conducted for more identification of this microorganism in food and its products in Iraq. Conventional methods and commercial kits beside molecular techniques should be used to identify Providencia spp. in level species.

\section{Data Availability}

Data used to support the findings of this study can be obtained from the corresponding author on request.

\section{Conflicts of Interest}

The author declares no conflicts of interest.

\section{Acknowledgments}

The author would like to thank Dr. Nawal Dahd for helping in the laboratory to complete this research and Dr.Hanaa.

\section{References}

[1] V. S. Somvanshi, E. Lang, B. Sträubler et al., "Providencia vermicola sp. nov., isolated from infective juveniles of the entomopathogenic nematode Steinernema thermophilum," International Journal of Systematic and Evolutionary Microbiology, vol. 56, no. 3, pp. 629-633, 2006.

[2] P. Juneja and B. P. Lazzaro, "Providencia sneebia sp. nov. and Providencia burhodogranariea sp. nov., isolated from wild Drosophila melanogaster," International Journal of Systematic and Evolutionary Microbiology, vol. 59, no. 5, pp. 1108-1111, 2009.

[3] S. Khunthongpan, P. Sumpavapol, S. Tanasupawat, S. Benjakul, and A. H. Kittikun, "Providencia thailandensis sp. nov., isolated from seafood processing wastewater," The Journal of General and Applied Microbiology, vol. 59, no. 3, pp. 185-190, 2013.

[4] J. Jneid, S. Benamar, I. Pagnier, P. Y. Levy, J. P. Lavigne, and B. La Scolaa, "Draft genome sequence of Providencia heimbachae, isolated from a diabetic foot ulcer," Genome. Announc, vol. 4, no. 2, pp. e00276-16, 2016. 
[5] P. R. Krake and N. Tandon, "Infective endocarditis due to Providencia stuartii," Southern Medical Journal, vol. 97, no. 10, pp. 1022-1023, 2004.

[6] M. Yoh, J. Matsuyama, M. Ohnishi et al., "Importance of Providencia species as a major cause of travellers' diarrhoea," Journal of Medical Microbiology, vol. 54, no. 11, pp. 10771082, 2005.

[7] A. F. Koreishi, B. A. Schechter, and C. L. Karp, "Ocular infections caused by Providencia rettgeri," Ophthalmology, vol. 113, no. 8, pp. 1463-1466, 2006.

[8] D. Sharma, P. Sharma, and P. Soni, "First case report of Providencia Rettgeri neonatal sepsis," BMC Research Notes, vol. 10, no. 1, pp. 1-3, p2017.

[9] A. Shima, A. Hinenoya, W. Samosornsuk, S. Samosornsuk, N. Mungkornkaew, and S. Yamasaki, "Prevalence of Providencia strains among patients with diarrhea and in retail meats in Thailand," Japanese Journal of Infectious Diseases, vol. 69, no. 4, pp. 323-325, 2016.

[10] N. Sharma and D. Gupta, "Molecular characterization and antibiotic screening of Providencia stuartii isolated from the desert of Bikaner, northern India," Journal of Biotechnology and Biosafety, vol. 4, no. 1, pp. 339-344, 2016.

[11] A. Nahar, M. Marzan, M. Siddiquee, S. Nahar, K. S. Anwar, and S. Islam, "Multidrug resistant Providencia stuartii in chicken droppings: public health implications for poultry workers and associated communities in nearby Dhaka Metropolis, Bangladesh," Microbiology Research Journal International, vol. 14, no. 5, pp. 1-9, 2016.

[12] D. Kuczynski, "Occurrence of pathogenic bacteria in surface water of an urban river in Argentina ,Reconquista River, Buenos Aires," International Journalof Aquatic Science, vol. 7, no. 1, pp. 30-38, 2016.

[13] N. M. B. Rodrigues, G. F. Bronzato, G. S. Santiago et al., "The Matrix-Assisted Laser Desorption Ionization-Time of Flight Mass Spectrometry (MALDI-TOF MS) identification versus biochemical tests: a study with enterobacteria from a dairy cattle environment," Brazilian Journal of Microbiology, vol. 48, no. 1, pp. 132-138, 2017.

[14] F. S. A. Al-Mayahi and R. H. Ali, "Preliminary study of emergence MDR of Providenci spp.isolates producing ESBL, AmpC and MBL among patients with RTI and Wastewater in Al-Diwaniya city,Iraq," Biochemical and Cellular Archives, vol. 18, no. Supplement 1, pp. 1357-1368, 2018.

[15] A. A. Akinyemi, O. O. Oyelakin, and A. R. Oloyede, Gene Sequencing and Sensitivity of Bacteria in Tilapia Zilli from Ijaka-Oke Location on Yewa River, Aquaculture .America, Honolulu, HI, USA, 2017.

[16] O. O. Oyelakin, A. A. Akinyemi, J. K. Ekelemu, A. R. Oloyede, and B. O. Abiona, "Molecular characterization and haemolysis of bacteria associated with Tilapia zilli from Ijaka-Oke location on Yewa river," Journal of Experimental Agriculture International, vol. 11, no. 6, pp. 1-7, 2016.

[17] O. O. Ololade, O. O. Oyelakin, A. R. Oloyede, A. A. Idowu, A. AAkinyemi, and Y. A. Babarinde, "Gene sequencing and haemolysis of bacteria in Clarias gariepinus from Ajilete location on Yewa river," Annual Research \& Review in Biology, vol. 10, no. 4, pp. 1-8, 2016.

[18] D. H. Bergey and J. G. Holt, Bergey's Manual of Determinative Bacteriology, Williams and Wilkins, Baltimore, Maryland, 9th edition, 1994.

[19] E. Koneman, C. W. Washington, D. L. Stephen et al., Color Atlas and Textbook of Diagnostic Microbiology, Lippincott, Philadelphia, PA, 5th edition, 1997.
[20] G. Wauters, A. Boel, G. P. Voorn et al., "Evaluation of a new identification system, Crystal Enteric/Non-Fermenter, for gram-negative bacillification system, Crystal Enteric/NonFermenter, for gram-negative bacilli," Journal of Clinical Microbiology, vol. 33, no. 4, pp. 845-849, 1995.

[21] C. M. O'Hara, F. C. Tenover, and J. M. Miller, "Parallel comparison of accuracy of API 20E, Vitek GNI, MicroScan Walk/Away Rapid ID, and Becton Dickinson Cobas Micro ID-E/NF for identification of members of the family Enterobacteriaceae and common gram-negative, non-glucosefermenting bacilli," Journal of Clinical Microbiology, vol. 31, pp. 3165-3169, 1993.

[22] C. M. O'Hara, G. L. Westbrook, and J. M. Miller, "Evaluation of Vitek GNI+ and Becton Dickinson Microbiology Systems Crystal E/NF identification systems for identification of members of the family Enterobacteriaceae and other gramnegative, glucose-fermenting and non-glucose-fermenting bacilli," Journal of Clinical Microbiology, vol. 35, no. 12, pp. pp3269-3273, 1997.

[23] S. Bascomb, S. L. Abbott, J. D. Bobolis et al., "Multicenter evaluation of the MicroScan rapid gram-negative identification type 3 panel," Journal of Clinical Microbiology, vol. 35, no. 10, pp. 2531-2536, 1997.

[24] S. Pignato, G. M. Giammanco, F. Grimont, P. A. D. Grimont, and G. Giammanco, "Molecular characterization of the GeneraProteus, Morganella, andProvidencia by ribotyping," Journal of Clinical Microbiology, vol. 37, no. 9, pp. 2840-2847, 1999.

[25] N. Rajpara, B. M. Kutar, R. Sinha et al., "Role of integrons, plasmids and SXT elements in multidrug resistance of Vibrio cholerae and Providencia vermicola obtained from a clinical isolate of diarrhea," Frontiers in Microbiology, vol. 6, p. 57, 2015.

[26] G. Godebo, G. Kibru, and H. Tassew, "Multidrug-resistant bacterial isolates in infected wounds at jimma university specialized hospital, Ethiopia," Annals of Clinical Microbiology and Antimicrobials, vol. 12, no. 1, p. 17, 2013.

[27] I. Linhares, T. Raposo, A. Rodrigues, and A. Almeida, "Frequency and antimicrobial resistance patterns of bacteria implicated in community urinary tract infections: a ten-year surveillance study (2000-2009)," BMC Infectious Diseases, vol. 13, no. 1, p. 19, 2013.

[28] D. R. Kadavy, J. M. Hornby, T. Hawarkost, K. W. Nickerson, and W. N. Kenneth, "Natural antibiotic resistance of bacteria isolated from larvae of the oil fly, helaeomyia petrolei," Applied and Environmental Microbiology, vol. 66, no. 11, pp. 4615-4619, 2000.

[29] S. Shin, S. H. Jeong, H. Lee, J. S. Hong, M. J. Park, and W. Song, "Emergence of multidrug-resistant Providencia rettgeri isolates co-producing NDM-1 carbapenemase and PER-1 extended-spectrum $\beta$-lactamase causing a first outbreak in Korea," Annals of Clinical Microbiology and Antimicrobials, vol. 17, no. 1, 20 pages, 2018.

[30] H. Barrios, U. Garza-Ramos, F. Reyna-Flores et al., "Isolation of carbapenem-resistant NDM-1-positive Providencia rettgeri in Mexico," Journal of Antimicrobial Chemotherapy, vol. 68, no. 8, pp. 1934-1936, 2013.

[31] M. Abdallah, R. Alhababi, N. Alqudah, B. Aldyyat, and A. Alharthy, "First report of carbapenem-resistant Providencia stuartii in Saudi Arabia," New Microbes and New Infections, vol. 26, pp. 107-109, 2018.

[32] V. S. Tshisevhe, M. R. Lekalakala, N. Tshuma, S. Janse van Rensburg, and N. Mbelle, "Outbreak of carbapenem-resistant 
Providencia rettgeri in a tertiary hospital," South African Medical Journal, vol. 107, no. 1, pp. 31-33, 2017.

[33] S. Marjan, K. K. Das, S. K. Munshi, and N. Noor, "Drugresistant bacterial pathogens in milk and some milk products," Nutrition and Food Science, vol. 44, no. 3, pp. 241-244, 2014.

[34] M. Aebi, B. Van Den Borne, A. Raemy, A. Steiner, P. Pilo, and M. Bodmer, "Mycoplasma bovis infections in Swiss dairy cattle: a clinical investigation," Acta Veterinaria Scandinavica, vol. 57, no. 1, p. 10, 2015.

[35] M. Hamiroune, A. Berber, and S. Boubekeur, "Contribution to the study of staphylococcus contamination of cows' milk on a number of farms in Algiers: its impact on human health," Revue Scientifique Et Technique, vol. 33, no. 3, pp. 1035-1041, 2014.

[36] F. F. Guimarães, D. B. Nóbrega, V. B. Richini-Pereira, P. M. Marson, J. C. De Figueiredo Pantoja, and H. Langoni, "Enterotoxin genes in coagulase-negative and coagulasepositive staphylococci isolated from bovine milk," Journal of Dairy Science, vol. 96, no. 5, pp. 2866-2872, 2013.

[37] I. Verdier-Metz, G. Gagne, S. Bornes et al., "Cow teat skin, a potential source of diverse microbial populations for cheese production," Applied and Environmental Microbiology, vol. 78, no. 2, pp. 326-333, 2012.

[38] M. Vacheyrou, A.-C. Normand, P. Guyot, C. Cassagne, R. Piarroux, and Y. Bouton, "Cultivable microbial communities in raw cow milk and potential transfers from stables of sixteen French farms," International Journal of Food Microbiology, vol. 146, no. 3, pp. 253-262, 2011.

[39] P. Mahlangu, M. Naomi, and K. John, "Prevalence, risk factors, and antibiogram of bacteria isolated from milk of goats with subclinical mastitis in thika east subcounty, Kenya," Journal of Veterinary Medicine, vol. 2018, Article ID 3801479, 8 pages, 2018.

[40] R. Saidi, D. Khelef, and R. Kaidi, "Bovine mastitis: prevalence of bacterial pathogens and evaluation of early screening test," African Journal of Microbiology Research, vol. 7, no. 9, pp. 777-782, 2013.

[41] Y. Yi, H. W. Park, S. Shrestha et al., "Identification of two entomopathogenic bacteria from a nematode pathogenic to the oriental beetle, Blitopertha orientalis," Journal of Microbiology and Biotechnology, vol. 17, no. 6, p. 968, 2007.

[42] S. Mukherjee, D. Kumar, A. K. Nanda, and R. Chakraborty, "16S rRNA gene sequence analyses of the metagenome derived from waters of river Mahananda at Siliguri: an approach to understand bacterial diversity," Indian Journal of Biotechnology, vol. 12, pp. 80-88, 2013.

[43] CLSI (Clinical and Laboratory Standards Institute), PerformanceStandards for Antimicrobial Susceptibility Testing, Twenty-Fourth Informational Supplement. CLSI Document M100, 29th edition, Wayne, PA, 2019.

[44] EUCAST (The European Committee on Antimicrobial Susceptibility Testing), Disk Diffusion Method for Antimicrobial Susceptibility Testing,Version 7.0, http://www.eucast.org.2019.

[45] A. P. Magiorakos, A. Srinivasan, R. B. Carey et al., "Multidrugresistant, extensively drug-resistant and pan drug resistant bacteria: an international expert proposal for interim standard definitions for acquired resistance," Clinical Microbiology and Infection, vol. 18, no. 3, pp. 268-281, 2012.

[46] P. H. Krumperman, "Multiple antibiotic resistance indexing of Escherichia coli to identify high-risk sources of fecal contamination of foods," Applied and Environmental Microbiology, vol. 46, no. 1, pp. 165-170, 1983.
[47] G. Cornaglia, S. Frugoni, A. Mazzariol, E. Piacentini, A. Berlusconi, and R. Fontana, "Activities of oral antibiotics on Providencia strains isolated from institutionalized elderly patients with urinary tract infections," Antimicrobial Agents and Chemotherapy, vol. 39, no. 12, pp. 2819-2821, 1995.

[48] K. Cui, X. Fu, Z. Li, and C. Li, "An investigation into food poisoning caused by Providencia rettgeri," Litetural Infections Preventive Medicine, vol. 6, p. 116, 2000.

[49] R. Chlibek, J. Jirous, and J. Beran, "Diarrhea outbreak among Czech Army Field Hospital personnel caused by Providencia alcalifaciens," Journal of Travel Medicine, vol. 9, pp. 151-152, 2002.

[50] S. Mahrouki, H. Chihi, A. Bourouis, M. Ben Moussa, and O. Belhadj, "First characterization of a Providencia stuartii clinical isolate from a Tunisian intensive care unit coproducing VEB-1-a, OXA-2, qnrA6 and aac $\left(6^{\prime}\right)$-Ib-cr determinants," Brazilian Journal of Infectious Diseases, vol. 18, no. 1, pp. 211-214, 2014.

[51] A. Shima, A. Hinenoya, M. Asakura, A. Nagita, and S. Yamasaki, "Prevalence of Providencia strains among children with diarrhea in Japan," Japanese Journal of Infectious Diseases, vol. 65, no. 6, pp. 545-547, 2012.

[52] R. Ramkumar, M. Ravi, C. Jayaseelan, A. Abdul Rahuman, C. Anandhi, and P. Perumal, "Description of Providencia vermicola isolated from diseased Indian major carp, Labeo rohita (Hamilton, 1822)," Aquaculture, vol. 420-421, pp. 193-197, 2014.

[53] M. M. Shah, E. Odoyo, P. S. Larson et al., "First report of a foodborne Providencia alcalifaciens outbreak in Kenya," Journal of Tropical Medicine and Hygiene, vol. 93, no. 3, pp. 497-500, 2015.

[54] H. Di, S. Liang, Q. Li et al., "Providencia in retail meats from Guangzhou, China and Osaka, Japan: prevalence, antimicrobial resistance and characterization of classes 1, 2 and 3 integrons," Journal of Veterinary Medical Science, vol. 80, no. 5, pp. 829-835, 2018.

[55] N. W. Hammood and I. A. J. Ibrahim, "Bacterial content in gut for different species of fish collecting from tigris river in Baghdad city, Iraq," Tikrit Journal of Pure Science, vol. 23, no. 3, pp. 33-37, 2015.

[56] I. E. Aibinu, Y. Pfeifer, F. Ogunsola, T. Odugbemi, W. Koenig, and B. Ghebremedhin, "Emergence of $\beta$-lactamases OXA-10, VEB-1 and CMY in Providencia spp. from Nigeria," Journal of Antimicrobial Chemotherapy, vol. 66, no. 8, pp. 1931-1932, 2011. 